\title{
PW03-020 - A decade of ANTI-IL-1 therpay for CAPS in the UK
}

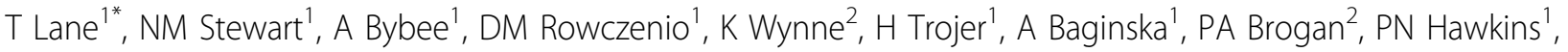 \\ HJ Lachmann ${ }^{1}$
}

From 7th Congress of International Society of Systemic Auto-Inflammatory Diseases (ISSAID) Lausanne, Switerland. 22-26 May 2013

\section{Introduction}

In October 2002, the first patient with CAPS was treated successfully with the anti-IL-1 agent anakinra at our Centre in the UK, and in 2009 a nationally funded canakinumab treatment service initiated for CAPS in England. By the end of 2012, 82 symptomatic individuals have been assessed at our Centre.

\section{Objectives}

To describe our experience, and outcomes of 82 individuals with clinical CAPS, including treatment and natural history.

\section{Methods}

We examined all available medical and laboratory records.

\section{Results}

Of 82 patients with clinical CAPS a pathogenic sequence variant (PSV) was detected in 77 (94\%); 17 PSVs were identified, the commonest were R260W (27\%), A439V (23\%), T348M (17\%), V198M (5\%). 5 patients had no PSV detected on Sanger sequencing: 3 children with CINCA and 2 patients with adult onset clinical MWS. 90\% were white, 8.5\% South Asian and 1\% African. 46 (56\%) gave a positive family history. There were 8 CINCA cases, $4 \mathrm{MWS} /$ CINCA overlap (75\% T348M), 59 MWS (62\% A439V, 31\% R260W, 19\% T348M, 5\% V198M) and 11 FCAS (36\% A439V, 27\% R260W, 9\% V198M). Hearing impairment was present in $31(38 \%)$; $12 / 14$ patients $(86 \%)$ with $\mathrm{T} 348 \mathrm{M}, 1 / 19(5 \%)$ of $\mathrm{A} 439 \mathrm{~V}$, $3 / 22(14 \%)$ of R260W and 3/4 (75\%) of V198M.

51 patients are receiving canakinumab (20 having converted from anakinra). Over a median follow up (FU)

${ }^{1}$ National Amyloidosis Centre, University College London, UK Full list of author information is available at the end of the article period of 28 months (IQR 15-40), 43 (84\%) have experienced complete remission (CR) of disease activity whilst the remainder $(8,16 \%)$ have experienced partial remission (PR), defined as good but incomplete resolution of symptoms or serum inflammatory markers. 15 (29\%) patients are being treated with double the licensed dose - 4 CINCA (including 2 children), 4 MWS/CINCA overlap, 6MWS (including 2 children) and 1 FCAS with uveitis. 3 patients have discontinued canakinumab and are currently on no treatment (one each with A439V, T348M, R260W) due to: an episode of diverticulitis; pregnancy; a desire for a treatment break. Serious adverse events included infections (diverticulitis, UTI, tonsillitis).

24 patients are on anakinra and over a median FU of 47 months (IQR 12-72) 20 remain in CR and 4 in PR. 6 patients have previously tried canakinumab; 2 had CR but were converted due to: planned pregnancy; planned insertion of a ventricular peritoneal shunt. One adult CINCA patient with a good PR could not tolerate travel to our Centre. A female with mutation negative MWS previously in CR on anakinra opted for a trial of canakinumab, but developed a massive disease flare resulting in hospitalisation. She subsequently reverted to anakinra and is once again in CR. 2 males (A439V, T346I) discontinued canakinumab due to: lack of efficacy; development of major systemic inflammation and a morphea like rash. On anakinra the former remains in PR whilst the latter has experienced CR.

2 children with mild R260W disease have declined treatment.

\section{Conclusion}

In this series T348M underlies more severe disease than the other common mutations. A decade of IL-1 blockade confirms its efficacy and relative safety in CAPS across the clinical severity spectrum. Canakinumab is 
the more popular drug due to its long action; however, a small number of patients are unresponsive to this therapy, suggesting a possible role of IL- $1 \alpha$.

\section{Disclosure of interest}

None declared.

\section{Authors' details}

${ }^{1}$ National Amyloidosis Centre, University College London, UK. ${ }^{2}$ Rheumatology and Vasculitis, Great Ormond Strret Hospital NHS Trust, London, UK

Published: 8 November 2013

doi:10.1186/1546-0096-11-S1-A246

Cite this article as: Lane et al:: PW03-020 - A decade of ANTI-IL-1 therpay for CAPS in the UK. Pediatric Rheumatology 2013 11(Suppl 1): A246.

Submit your next manuscript to BioMed Central and take full advantage of:

- Convenient online submission

- Thorough peer review

- No space constraints or color figure charges

- Immediate publication on acceptance

- Inclusion in PubMed, CAS, Scopus and Google Scholar

- Research which is freely available for redistribution

Submit your manuscript at www.biomedcentral.com/submit 